\title{
Use of restriction fragment length polymorphisms (RFLPs) to distinguish between nematodes of pathogenic significance
}

\author{
M. L. CAMERON, P. LEVY, T. NUTMAN*, C. R. VANAMALA $\dagger$, \\ P. R. NARAYANAN $\dagger$ and T.V. RAJAN \\ Departments of Pathology and Microbiology and Immunology, Albert Einstein College \\ of Medicine, 1300 Morris Park Ave., Bronx, New York 10461
}

(Accepted 29 September 1987)

\section{S UMMARY}

The availability of restriction fragment length polymorphisms (RFLPs) would be useful for studying the extent of diversity among morpholgically indistinguishable populations of filarial parasites. Such polymorphisms may be useful in correlating various physiological and clinical differences with parasite heterogeneity. In order to identify such RFLPs, we isolated DNA from microfilaria of 6 filarial species (Acanthocheilonema viteae, Brugia malayi, Brugia pahangi, Dirofilaria immitis, Litomosoides carinii and Setaria digitatum), digested the DNA with several restriction endonucleases, prepared Southern blots and probed with ${ }^{32} \mathrm{P}$-labelled DSA probes. The patterns of fragments generated using two restriction endonucleases, Mbo I and Taq I, in combination with two probes, rDNA from the free-living soil nematode Caenorhabditis elegans, and pBM103, an anonymous DNA probe from B. malayi, unequivocally distinguish between all 6 of the species. To ensure that the differences we observed between the species represent true interspecies variation rather than fortuitous individual variations we analysed DNA from several individual B. malayi and B. pahangi worms. The individual $B$. malayi worms demonstrated restriction profiles that were invariant, as did the individual $B$. pahangi worms, demonstrating that the differences we observed were true interspecies variations.

\section{N T R O D U C T I O N}

Filariasis is a major public health problem in a number of tropical and subtropical countries, afflicting several hundred million people. The microfilariae of the parasites which infect humans are distinctive enough so that species can usually be identified on morphological criteria alone. However, there are some situations in which lightmicroscopic morphology is inadequate. First, in some geographical areas where multiple parasitic species coexist definitive species diagnosis can be difficult. Second, although there is no firm evidence at the present time, certain observations suggest that identical parasite populations may differ in ways which affect the clinical manifestations or course of disease. For instance, microfilariae of Wuchereria bancrofti that infect patients in India and in the Cooke Islands cannot be distinguished from each other by morphology. However, the biology of the parasite, as demonstrated by the periodicity in peripheral circulation, is quite different. Based on this and other features, Otteson (1984) has suggested that there may be several races or substrains of these organisms. Clearly, it would be useful to have an additional means of distinguishing amongst the known species. Ideally this technique should be able to discriminate between strains and subspecies. One method of determining inter-species differences, as well as discerning subtle differences within populations, is to use DNA probes.

* Present address: Laboratories of Parasitic Diseases, NIAID, NIH, Bethesda, Maryland.

$\dagger$ Present address: Tuberculosis Research Center, Madras, India. 
There are two approaches to the use of DNA probes in species identification. One approach is to generate probes that are specific for the DNA of a given species and which will not hybridize to DNA from others. In such cases, hybridization of parasite DNA obtained from a patient or a suspected animal reservoir will definitively identify the organism for which the probe is specific, while ruling out other species. For example, species-specific probes have been generated for Brugia malayi (McReynolds, DeSimone \& Williams, 1986; Sim, Mak, Cheong, Sutanto, Kurniawan, Marwoto, Franke, Campell, Wirth \& Peissens, 1986; Sim, Piessens \& Wirth, 1986) and Onchocerca volvulus (Perler \& Karam, 1986); for the latter, a strain-specific probe, able to distinguish between forest and Savannah forms, has recently been reported (Ertmann, Unnasch, Greene, Albiez, Boateng, Denke, Ferraroni, Karam, Schulz-Key \& Williams, 1987). The alternative approach is to generate probes that hybridize with the DNA of all filarial parasites, but can distinguish between the DNA of various parasites on the basis of restriction fragment length polymorphisms (RFLPs). We feel that the latter approach is more useful for taxonomic studies, because it can yield information about the degree of genetic similarity between different species. (Another technique which has been used to study parasite populations, the examination of isozyme distribution, suffers from the drawback that it is nearly impossible to distinguish genetic from epigenetic phenomena.) In this communication we describe the use of two probes that crosshybridize with all nematode DNAs we have tested, but readily distinguish among the various organisms by RFLPs, using restriction endonucleases. One of the probes was generated using DNA from the human parasite $B$. malayi, cloned into the plasmid vector pUC 18. The other probe is ribosomal DNA (rDNA) from the free-living soil nematode Caenorhabditis elegans, cloned into the plasmid vector pBR313 (Files \& Hirsh, 1981).

\section{MATERIALS AND METHODS}

\section{Construction of a Shotgun Library of B. malayi DNA into pUC 18}

B. malayi adult worms were obtained in the frozen state from Dr W. McCall, University of Georgia, through the US/Japan collaborative programme in filariasis. Worms were thawed upon arrival, minced to small pieces with scissors and resuspended in $5 \mathrm{ml}$ of TE (10 mM Tris, $\mathrm{pH} 75,5 \mathrm{~mm}$ EDTA). $\mathrm{NaCl}$ was added to a final concentration of $150 \mathrm{mM}$, SDS to $1 \%$, and 2 mercaptoethanol to $0.5 \%$. The reaction mixture was vortexed briefly and incubated at $65{ }^{\circ} \mathrm{C}$ for $10 \mathrm{~min}$. Proteinase $\mathrm{K}$ (proteinase type XI from Sigma Chemical Co.) was added to a concentration of $50 \mu \mathrm{g} /$ $\mathrm{ml}$. The reaction mixture was again vortexed briefly, re-incubated at $65{ }^{\circ} \mathrm{C}$ for $2.5 \mathrm{~h}$, and subjected sequentially to one extraction with chloroform : phenol : isoamyl alcohol (25: $25: 1$ ), and two extractions with TE-saturated diethyl ether. Sodium acetate was added to a concentration of $0.3 \mathrm{M}$ and the nucleic acids precipitated by the addition of 2 volumes of absolute ethanol. The DNA that came out of solution was removed with a pasteur pipette, transferred to a fresh tube and washed with $70 \%$ ethanol. The DNA was pelleted, dried in vacuo, and rehydrated in $2 \mathrm{ml}$ of TE (10 mM Tris, $\mathrm{pH} 7.5,5 \mathrm{mM}$ EDTA). When the DNA was completely in solution, ribonuclease, previously boiled to destroy any contaminating deoxyribonuclease, was added to a final concentration of $20 \mu \mathrm{g} / \mathrm{ml}$, and the reaction mixture was incubated for $30 \mathrm{~min}$ at $37{ }^{\circ} \mathrm{C}$ and finally reincubated with proteinase $\mathrm{K}$ and extracted as described above. B. malayi DNA was then digested to completion with the restriction endonuclease Sau 3A, according to the instructions of the manufacturer (Sew England Bio Labs). The DNA was ligated to 


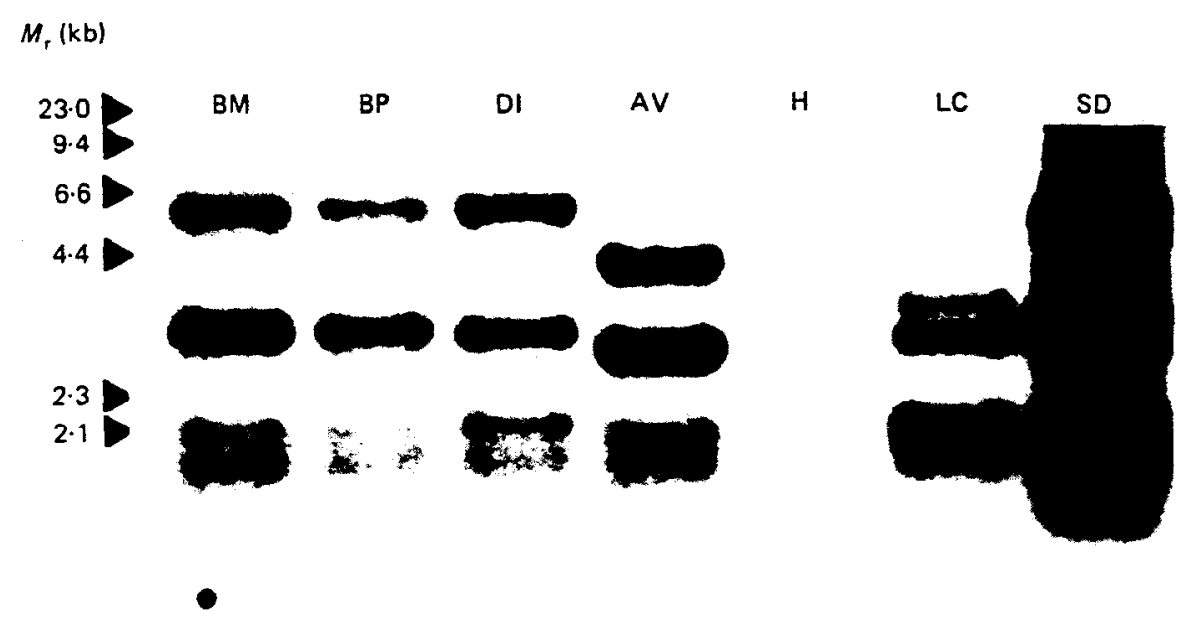

Fig. 1. DNA from Brugia malayi (BM), B. pahangi (BP), Dirofilaria immitis (DI). Acanthocheilonema viteae (AV), human (H), Litomosoides carinii (LC) and Setaria digitatum (SD) was digested with Msp I, electrophoresed through a $1.0 \%$ agarow gel blotted on to nitrocellulose and probed with ${ }^{32} \mathrm{P}$-labelled Caenorhabditis elegans rDNA. Molecular weight markers and their sizes (in $\mathrm{kb}$ ) are shown on the left.

Bam HI cut and alkaline phosphatase-treated pUC 18 in $50 \mathrm{~mm}$ Tris, $\mathrm{pH} 7.5,5 \mathrm{~mm}$ $\mathrm{MgCl}_{2}, 1 \mathrm{~mm}$ ATP, $10 \mathrm{~mm}$ DTT and 4\% polyethylene glycol 8000. Ligation proceeded at $16{ }^{\circ} \mathrm{C}$ overnight, and the ligated DNA was used to transform competent Escherichia coli K12 JM 83. The transformed bacteria were plated onto indicator plates and white colonies were harvested as potential inert-containing clones. A number of them were tested to confirm the presence of inserts. The insert sizes ranged from 500 base-pairs to almost 2 kilobases $(\mathrm{kb})$.

\section{Southern blot analysis}

Southern blot analyses were performed on DNA obtained from Acanthocheilonema viteae (formerly known as Dipetalonema viteae), B. malayi, Brugia pahangi, C. elegans, Dirofilaria immitis, Setaria digitatum and Litomosoides carinii. In most cases DNA was extracted from the worms as described above. All worms, with two exceptions (C. elegans and S. digitatum) were obtained as frozen specimens from $\mathrm{Dr} \mathrm{W}$. McCall, University of Georgia through the US/Japan collaborative programme in filariasis. $S$. digitatum was obtained from an abattoir in Madras, India, as live worms dissected from the abdomen of cows. The fresh live worms were frozen and thawed repeatedly to disrupt them, following which DNA was extracted as described above for B. malayi.

DNA from the various nematodes was digested to completion with a variety of restriction endonucleases using conditions recommended by the manufacturer. The DNA was subjected to horizontal gel electrophoresis in agarose, transferred to nitrocellulose paper and probed with ${ }^{32} \mathrm{P}$-labelled plasmid from either the $B$. malayi library or the ribosomal DNA (rDNA) from C. elegans (kindly provided by Dr Scott Emmons). The latter is a Barn HI fragment containing a single $7 \mathrm{~kb}$ rDNA repeat unit (18s, $5.8 \mathrm{~s}$ and $26 \mathrm{~s}$ ribosomal genes as well as non-transcribed spacer sequence) cloned into the plasmid vector pBR313 (Files \& Hirsh, 1981). Probes were labelled by nicktranslation as described in an earlier publication (Rajan, Halay, Potter, Evans, Seidman \& Margulies, 1983). 


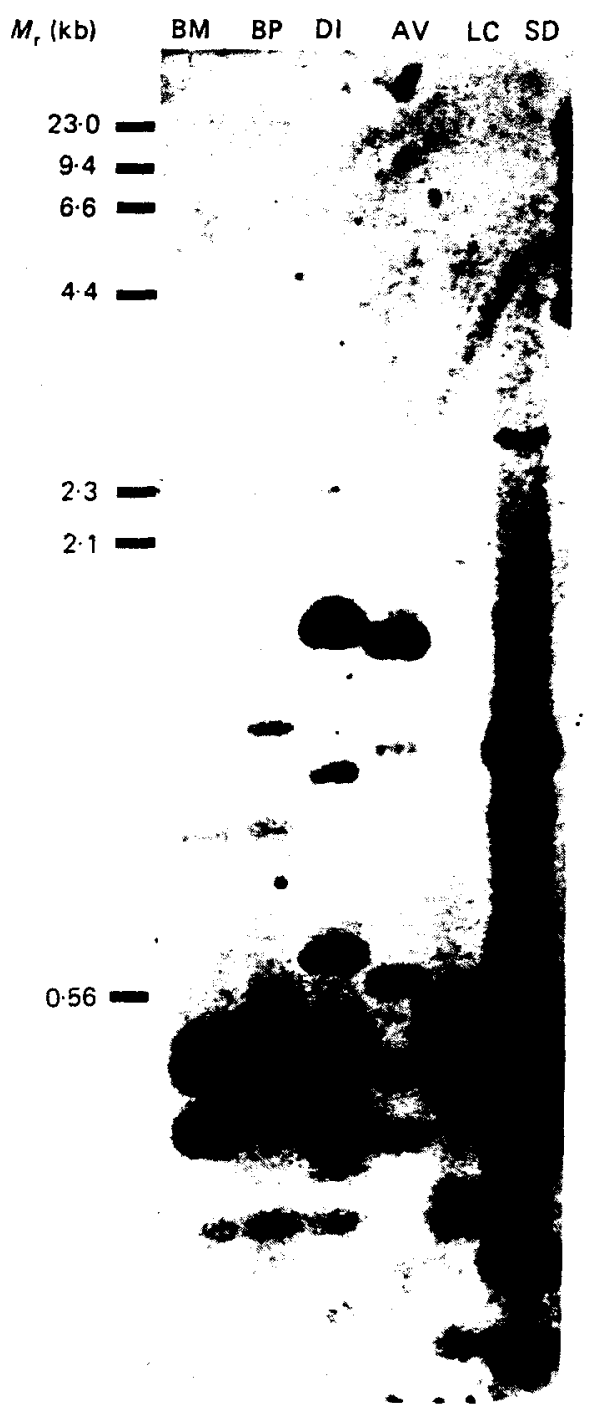

Fig. 2. DNA from Brugia malayi (BM), B. pahangi (BP), Dirofilaria immitis (DI), Acanthocheilonema viteae (AV), Litomosoides carinii (LC), and Setaria digitatum (SD) was digested with Taq I, electrophoresed through a $12 \%$ agarose gel, blotted on to nitrocellulose and probed with ${ }^{32} \mathrm{P}$-labelled Caenorhabditis elegans rDNA. Molecular weight markers and their sizes (in $\mathrm{kb}$ ) are shown on the left.

\section{RES ULT S}

\section{Isolation of $\mathrm{pBm} 103$}

Sau 3A digested DSA isolated from B. malayi was cloned into Barn HI cut pUC 18 as described above. Several random clones were picked and the inserts analysed by restriction mapping. In our primary analysis of 46 clones, several different recombinant plasmids were isolated repeatedly, which indicates that they represent sequences repeated in the genome. One of them, pBm103, represented 5 of the 46 clones analysed and contained an insert of 720 base-pairs. We chose to characterize this in greater detail because it hybridized to all nematode DNAs tested so far. 


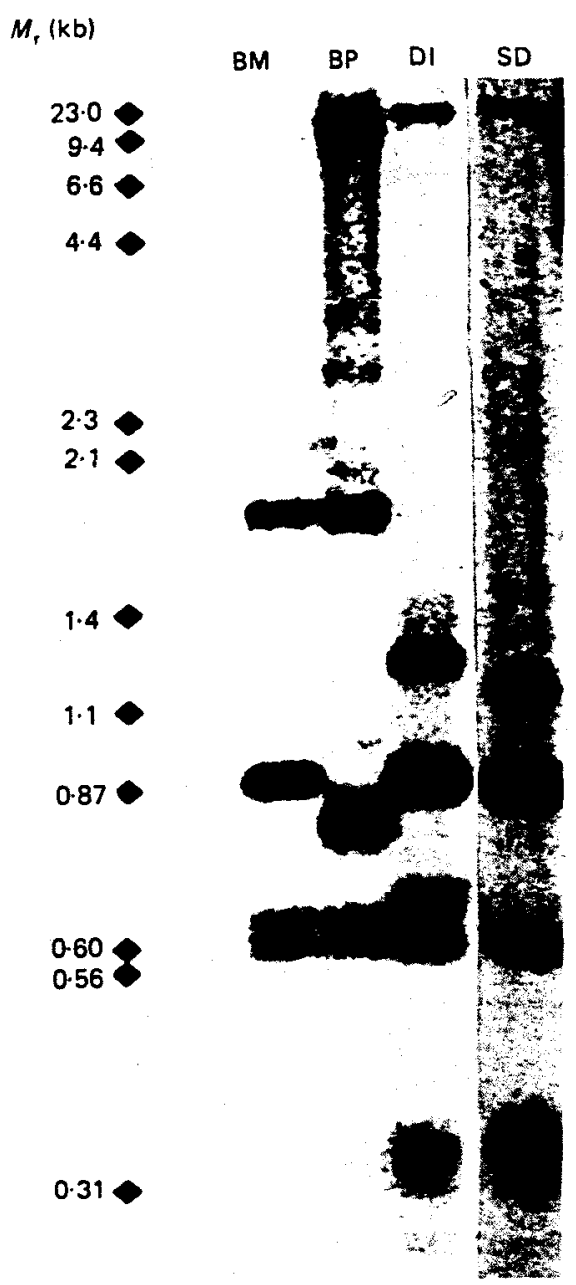

Fig. 3. DNA from Brugia malayi (BM), B. pahangi (BP), Dirofilaria immitis (DI), and Setaria digitutum (SD) was digested with Mbo I, electrophoresed through a $1.5 \%$ agarose gel and probed with ${ }^{32}$ P-labelled Caenorhabditis elegans rDNA. Molecular weight markers and their sizes (in $\mathrm{kb}$ ) are shown on the left.

\section{Analysis of genomic DNA with C. elegans rDNA}

Southern blots of nematode genomic DNA digested with some of the commonly used restriction enzymes displayed little polymorphism when probed with rDNA; an example is the Msp I digest shown in Fig. 1. Note that all worms had a doublet at about $2 \mathrm{~kb}$, a strong band at about $3 \mathrm{~kb}$, and another strong band whose size varied from about 3.5 to $6 \mathrm{~kb}$. With this and many other enzymes the patterns are very similar, and are therefore not useful for species identification. However, some enzymes, particularly Taq I (Fig. 2) and Mbo I (Fig. 3) resulted in species-specific polymorphisms, With Taq I, B. pahangi and B. malayi shared doublets at 0.5 and $0.4 \mathrm{~kb}$ and minor bands at $1.8,1.0$ and $0.3 \mathrm{~kb} ; D$. immitis had major bands at 1.9 and $0.7 \mathrm{~kb}$, doublets at 0.5 and $0.4 \mathrm{~kb}$, and minor bands at 3.0 and $1.2 \mathrm{~kb} ;$ A viteae had strong bands at 1.8, 0.6, 0.5 and $0.4 \mathrm{~kb}$ and a minor band at $1.3 \mathrm{~kb} ; L$. carinii had a very strong $0.5 \mathrm{~kb}$ doublet and a $0.3 \mathrm{~kb}$ doublet; and $S$. digitatum had very strong bands, some of them doublets, at 1.4, 


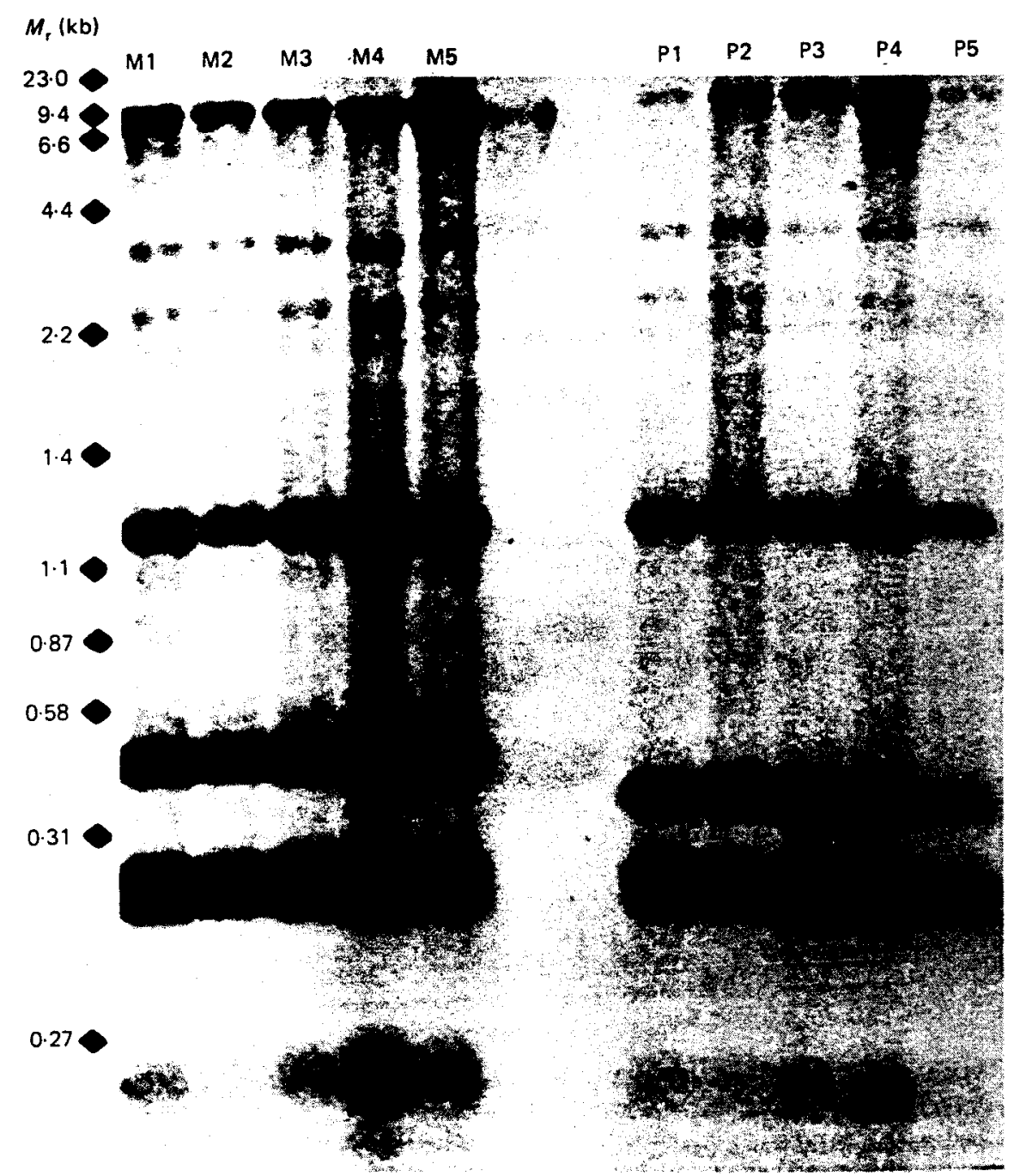

Fig. 4. DNA was prepared individually from 5 Brugia malayi adult worms (M1-M5) and 5 B. pahangi adult worms (P1-P5). digested with Mbo I. blotted on to nitrocellulose, electrophoresed through a $1.2 \%$ agarose gel and probed with ${ }^{32} \mathrm{P}$-labelled Caenorhabditis elegans rDNA. Molecular weight markers and their sizes (in kb) are shown on the left.

$1.2,0.7,0.5,0.4,0.24$ and $0.18 \mathrm{~kb}$. To see whether the polymorphisms between the closely related species $B$. malayi and $B$. pahangi visible in Fig. 2 were genuine interspecies differences, we prepared $B$. malayi and $B$. pahangi DNA from taps of different jirds, digested the DNA with Taq I and performed Southern blot analysis with ${ }^{32} \mathrm{P}$-labelled $C$. elegans rDNA. We found that the apparent interspecies difference was in fact an individual, rather than an interspecies, polymorphism (data not shown).

The enzyme Mbo I also resulted in species-specific RFLPs with the rDNA probe (Fig. 3). Although each species exhibited a doublet at around $0.6 \mathrm{~kb}$ each had at least 1 unique band. To see whether the difference between B. malayi and B. pahangi observed with this enzyme/probe combination was a true interspecies difference, we digested the DNA of individual B. malayi and B. pahangi adults with Mbo I, ran them on a Southern blot, and probed with rDNA (Fig. 4). We observed a subtle but consistent 


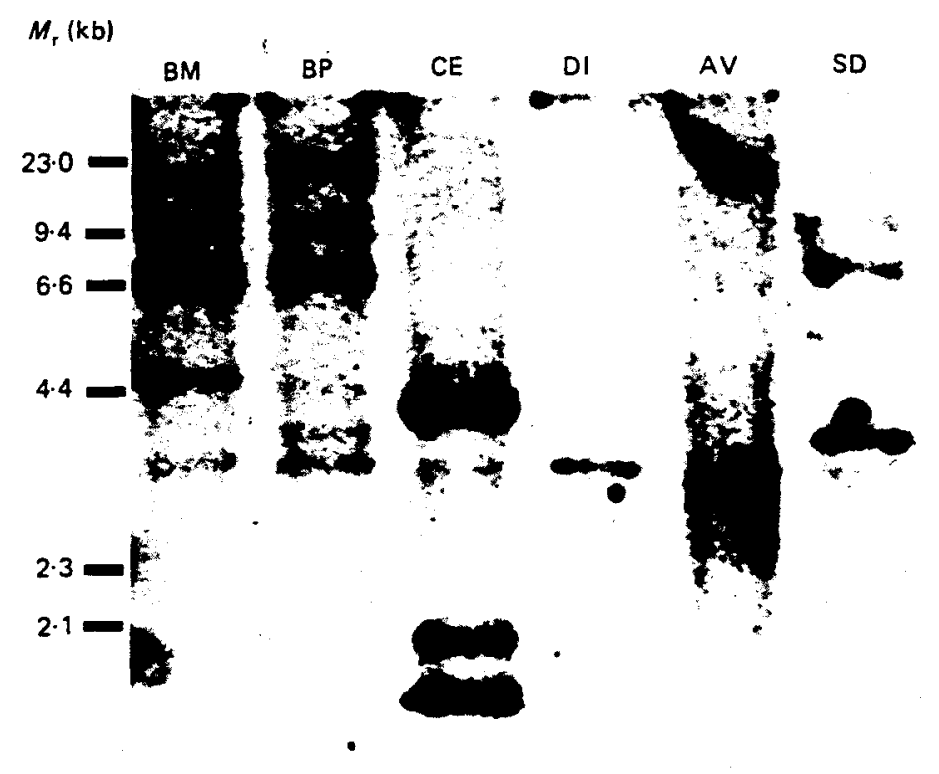

Fig. 5. DNA from Brugia malayi (BM), B. pahangi (BP), Caenorhabditis elegans (CE), Dirofilaria immitis (DI), Acanthocheilonema viteae (AV) and Setaria digitatum (SD) was digested with Hind III, electrophoresed through a $1.2 \%$ agarose gel and probed with ${ }^{32} \mathrm{P}$ labelled pBm103. Molecular weight markers and their sizes (in kb) are shown on the left.

polymorphism: one major band of $B$. malayi was about $0.70 \mathrm{~kb}$, while that of B. pahangi was about $0.65 \mathrm{~kb}$.

\section{Analysis of genomic DNA with pBm103}

When nick translated and used to probe Southern blots, pBm103 hybridized to the DNA of all nematodes tested, including the free-living soil nematode, C. elegans. It did not hybridize to human or jird DSA (data not shown).

When used on Southern blots of various nematode DNAs cut with various enzymes, pBm103 hybridized to 2-4 fragments, many of which were considerably larger than the size of the insert, but little or no polymorphism was evident. In contrast, when used in combination with Hind III or Mbo I, it yielded patterns of restriction fragments that were unique for each species tested. The results obtained using Hind III are shown in Fig. 5. Note that each species gave a unique pattern: B. malayi had a major band at $8 \mathrm{~kb}$ and minor bands at $20,12.5$ and $3.5 \mathrm{~kb} ; B$. pahangi had a similar pattern but differed from $B$. malayi by the presence of a band at $3.7 \mathrm{~kb}$ and a fainter band at $4.5 \mathrm{~kb}$, and by the absence of a band at $5 \mathrm{~kb}$; C. elegans had major bands at $4,1.5$ and $1.2 \mathrm{~kb} ; D$. immitis had a single band at $3.3 \mathrm{~kb} ; A$. viteae had a band at $3.4 \mathrm{~kb}$; and $S$. digitatum had bands at 10,8 , and $3.5 \mathrm{~kb}$. In order to ensure that the difference between $B$. malayi and $B$. pahangi is truly an interspecies difference, rather than fortuitous 


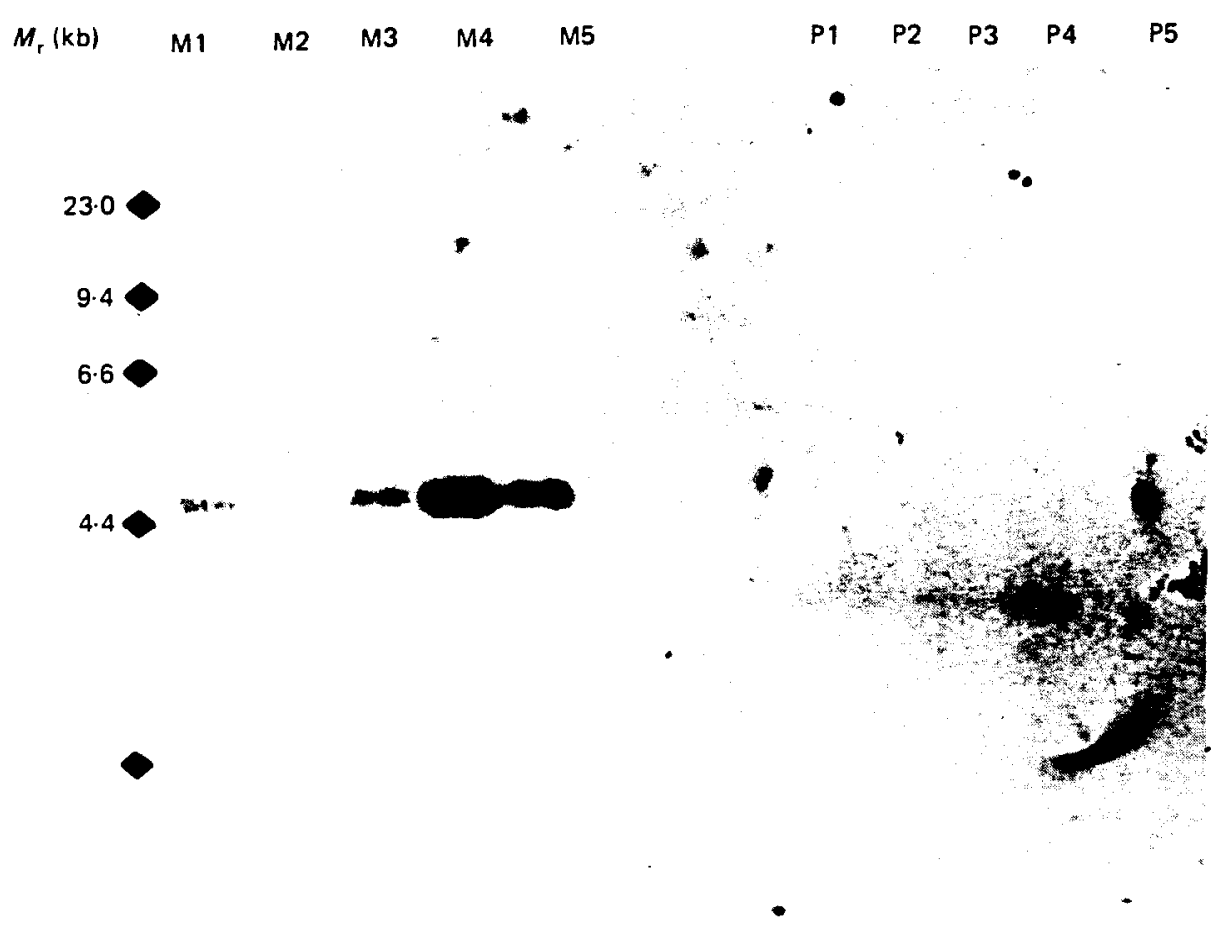

Fig. 6. DNA was prepared individually from 5 Brugia malayi adult worms (M1-M5) and 5 B. pahangi adult worms (P1-P5), digested with Mbo I, blotted on to nitrocellulose, electrophoresed through a $1.2 \%$ agarose gel and probed with ${ }^{32} \mathrm{P}-1$ abe11ed pBml03. Molecular weight markers and their sizes (in $\mathrm{kb}$ ) are shown on the left.

individual variation, we hybridized pBm103 to Southern blots of DNA from individual B. malayi and B. pahangi adults, digested with Hind III (data not shown). We demonstrated that $B$. malayi individuals were consistently distinguishable from B. pahangi individuals, with the former invariably possessing a band at $5 \mathrm{~kb}$, and the latter bands at 4.5 and $3.7 \mathrm{~kb}$. This suggests that the difference is truly a species variation.

Another restriction enzyme, $M b o$ I, also yielded a polymorphism which clearly distinguished $B$. malayi from $B$. pahangi. Fig. 6 shows DNA from individual adult B. malayi and B. pahangi, digested with $M b o$ I and probed with $\mathrm{pBm} 103$. A band at $0.6 \mathrm{~kb}$ is seen in $B$. malayi DNA whereas a fainter band is seen at $0.47 \mathrm{~kb}$ in B. pahangi.

\section{DISCUSSION}

In choosing probes to identify species of parasitic nematodes there were several considerations. A useful probe must have been sufficiently conserved during evolution to hybridize easily with a wide range of species, yet polymorphic enough to result in RFLPs. One complication is that the genomes of the filarial parasites are extremely A-T rich (Rothstein, Stoller \& Rajan, manuscript in preparation) and may have, as a result, a set of unusual codon preferences, so that heterologous sequences encoding even highly conserved proteins may prove impractical as probes. For instance, we have found that probes for collagen, myosin, actin and histone from C. elegans do not 
hybridize optimally to filariae DNA. However, we have identified two probes which allow a variety of filarial parasites (including the closely related species $B$. malayi and $B$. pahangi to be identified unambiguously on the basis of RFLPs.

We chose to characterize the plasmid which we call $\mathrm{pBml03}$, because it hybridizes to every nematode DNA tested thus far, including the non-filarial, free-living nematode $C$. elegans and because it arose repeatedly in random clones isolated from a shotgun library of Sau 3A library of $B$. malayi DNA. The conservation of this sequence in unrelated nematodes suggested that it might be an important coding sequence, since coding sequences tend to be conserved, whereas non-coding sequences tend to diverge rapidly and therefore do not cross-hybridize, even among closely related species. We have sequenced the entire insert in $\mathrm{pBm} 103$ by the dideoxy termination method (Sanger, Sicklen \& Coulson, 1977) and find no significant homology to any sequence, nucleotide or protein, in GenBank. Furthermore, it does not contain an open reading frame of any significant length. Regardless of its identity, we have shown that pBm 103 readily distinguishes among the DNA of various parasites by RFLPs. The enzymes Hind III and Mbo I give the most useful polymorphisms.

The conservation of rDNA demonstrated by the hybridization of the rDNA probe to all the nematodes is not surprising, since rDNA tends to be highly conserved in evolution (Long \& Dawid, 1980). However, the spacer sequences between the coding regions of the ribosomal cistron tend to diverge rapidly (Long \& Dawid, 1980), which probably accounts for the distinctive, species-characteristic restriction fragments shown above. The most useful enzymes for demonstrating this are Taq I and Mbo I; the latter distinguishes between $B$. malayi and $B$. pahangi as well as all the other nematodes tested. The large number of fragments visualized with this probe is particularly valuable, since this increases the amount of information per lane. Again, since the minor bands probably represent rare copies of the ribosomal repeats that have undergone mutations to diverge from the bulk of the multigene family, these might well show differences amongst subspecies and strains, should they exist.

We believe that the probes pBm103 and rDNA will prove useful in taxonomic studies, as well as in studies examining the genetic basis of parasite biology. We are now attempting to analyse the DNA of microfilaria obtained from patients with filariasis to determine whether any differences can be detected amongst the samples.

This work was made possible through a grant from the Irvington House Institute for Medical Research, and grants from the USPHS (CA 29194, AI 10702, and CA 13330). We would like to thank Ms Rosina Passela for her expert secretarial assistance.

\section{REFERENCES}

Ertmann, K. D., Unnasch, T. R., Greene, B. M., Albiez, E. J., Boateng, J., Denke, A. M., Ferraroni, J. J., Karam, M., Schulz-Key, H. \& Williams, P. N. (1987). A DNA sequence specific for forest form Onchocerca volvulus. Nature, London 327, 415-16.

FILES, J. C. \& HIRsh, D. (1981). Ribosomal DNA of Caenorhabditis elegans. Journal of Molecular Biology 149, 223-240.

LONG, E. O. \& DAWID, I. B. (1980). Repeated genes in eukaryotes. Annual Review of Biochemistry 49, 727-64.

McReynolds, L. A., DeSimone, S. M. \& Williams, S. A. (1986). Cloning and comparison of repeated DNA sequences from the human filarial parasite Brugia malayi and the animal parasite Brugia pahangi. Proceedings of the National Academy of Sciences, USA 83, 797-801.

OtTEson, E. A. (1964) Filariasis and tropical eosinophilia. In Tropical and Geographical Medicine (ed. K. S. Warren and A. A. Mahmond). New York: McGraw Hill. 
Perler, F. B. \& KARAM, M. (1986). Cloning and characterization of two Onchocerca volvulus repeated DNA sequences. Molecular and Biochemical Parasitology 21, 171-8.

Rajan, T. V., Halay, E. D., Potter, T. A., Evans, G. A., Seidman, J. G. \& Margulies, D. H. (1983). $H 2$ hemizygous mutants from a heterozygous cell line: role of mitotic recombination. $E M B O$ Journal 2, 1537-42.

SANGer, F., Nicklen, S. \& Coulson, A. R. (1977). DNA sequencing with chain-terminating inhibitors. Proceedings of the National Academy of Sciences, USA 74, 5463.

Sim, B. K. L., MaK, J. W., Cheong, W. H., Sutanto, I., Kurniawan, L., Marwoto, H. A., Franke, E., CAMpell, J. R., Wirth, D. F. \& Peissens, W. F. (1986). Identification of Brugia malayi in rectors with a species-specific DNA probe. American Journal of Tropical Medicine and Hygiene 35, 559-64.

Sim B. K. L., Piessens, W. F. \& WirTh, D. F. (1986). A DNA probe cloned in Escherichia coli for the identification of Brugia malayi. Molecular and Biochemical Parasitology 19, 117-23. 